
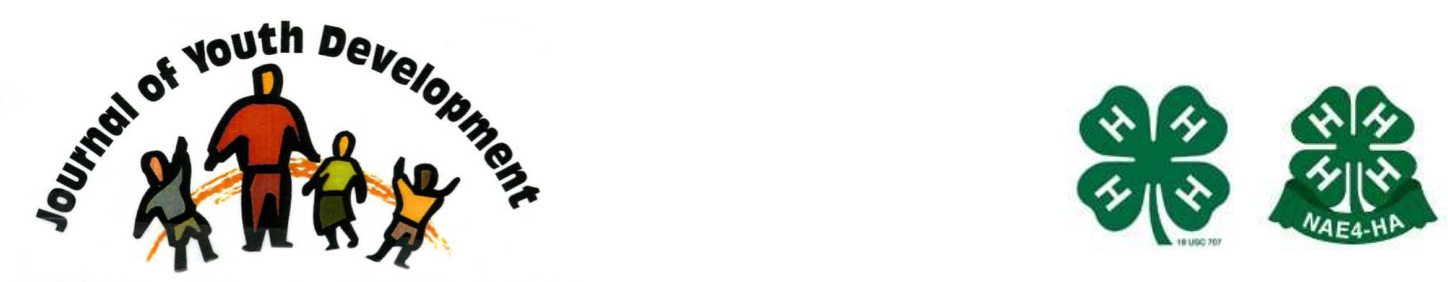

Bridging Research \& Practice

\title{
Envisioning and Implementing a Whole-School Youth Development Approach
}

\author{
Kristin Geiser \\ John W. Gardner Center for Youth and Their Communities \\ Stanford University \\ Stanford, CA \\ Christina O'Guinn \\ John W. Gardner Center for Youth and Their Communities \\ Stanford University \\ Stanford, CA
}




\title{
JOURNAL OF YOUTH DEVELOPMENT \\ bridging research and practice

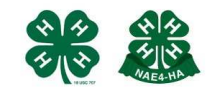

\section{Envisioning and Implementing a Whole-School Youth Development Approach}

\author{
Kristin Geiser and Christina O'Guinn \\ Stanford University
}

\begin{abstract}
Middle schools have the opportunity to positively impact the full development of young adolescents. Yet, initiatives that promote schools' rigorous attention to specific academic outcomes can make it difficult to attend to other important and interconnected domains of adolescent development. How might middle schools intentionally situate academics within the broader frame of youth development? Youth in the Middle (YiM), a partnership between John W. Gardner Center for Youth and Their Communities (JGC) at Stanford University and Kennedy Middle School in Redwood City, California, has pursued four areas of work that are central to developing a whole-school youth development approach. This article describes these work areas and offers preliminary evidence of progress.
\end{abstract}

\section{Introduction}

Young adolescents are in the midst of tremendous intellectual, physiological, emotional, and social growth and development. These domains are interdependent and interactive. Yet, in the midst of national, state, and district initiatives that promote rigorous attention to a particular set of academic outcomes, it is easy to slip into discourse and practice that suggest we can attend to one domain (e.g., the intellectual domain) in isolation from other domains. For example, research shows that a focus on academic achievement often translates to significantly reduced time devoted to anything other than reading and math instruction (Center on Educational Policy, 2009; Darling-Hammond, 2007; National Center for Educational Statistics, 2007; Teachers Network, 2007). In an effort to develop one domain, we tend to inadvertently betray what we know to be true about the link between multiple domains.

How, then, can middle schools attend to the important work of academic learning while leveraging growth in interdependent domains? This is what we at the John W. Gardner Center for Youth and Their Communities (JGC) at Stanford University refer to as a youth development approach. For nearly three years, we have had the privilege of coming alongside Kennedy Middle School as it has taken intentional steps to situate its work - inclusive of a significant 
focus on academic achievement - in the context of a school-wide youth development approach referred to as "Youth in the Middle" (YiM). In this article, we will summarize YiM's four signature work areas and offer preliminary evidence of progress.

\section{Core Work Areas}

\section{Work Area 1: Engage Cross-Functional Expertise in Support of Youth}

Youth, families, teachers, after-school staff, administrators and other school personnel all have important roles to play in supporting youth. As such, an important focus of YiM is to help adults in different roles understand, value, and ultimately seek the perspective and expertise of all who live and work in the school setting. YiM began with a visioning team of administrators, teachers, after-school staff, family engagement specialists, and community partners. During year one of the program, the sole purpose of this team was to develop a shared vision of a school that reflects a youth development approach. We found it very powerful to begin by focusing on participants' hopes for young people. For example, the team's first meeting began with consideration of this question: "Imagine your students in ten years... what would you hope to see?" By entering into the work this way, participants:

1) shared personally and authentically (and therefore began to feel invested in the process),

2) realized that they had the same hopes for their students as school members in different roles (and therefore began to see others as allies), and

3) acknowledged that their hopes for their students aligned with a vision of youth development (and therefore saw the youth development approach as resonant with their goals).

Intentional efforts to engage diverse expertise through the project enabled the adults in the setting to develop a sense that they did share a common vision for their students and for their setting. They also developed a real sense that their particular roles were important not because of what they could accomplish on their own - but because they were interconnected with others in ways that created a larger system designed to support young people.

\section{Work Area 2: Situate Academic Learning and Achievement in the Context of a Youth Development Approach}

Youth development often feels like an abstract idea rather than a very practical approach to teaching and learning. To address this, YiM encouraged the adults in the school setting to:

1) revisit their understanding of the conditions that promote academic learning and achievement,

2) make the connection between the conditions that promote learning and those that promote youth development across multiple domains,

3) see how their understanding of learning and achievement is supported and strengthened by a youth development approach,

4) identify the school's existing youth development-aligned practices and policies, and

5) develop a plan for expanding these practices.

Intentional efforts to situate academic learning and achievement in the context of a youth development approach honored the settings' commitment to multiple domains of development 
and reinforced the importance that they succeed in supporting the intellectual domain. A youth development framework interrupts the "either/or" binary that we often find in educational discourse - and offers a "yes/and" alternative - yes youth are developing in multiple domains, and schools need to be settings where youth thrive in the academic and intellectual domain. YiM cultivated our capacity to hold both of these truths.

\section{Work Area 3: Integrate Local and Research Knowledge}

As YiM participants began to intentionally implement a youth development approach throughout the school setting, they needed to better understand current research regarding teaching, learning, and young adolescent growth and development (research knowledge). They also needed to better understand their particular community and its unique strengths and challenges (local knowledge). Ultimately, they also needed the support to integrate research knowledge and local knowledge in ways that directly informed their practice. This was accomplished by:

1. tailoring professional development to identified school needs,

2. identifying opportunities to apply research knowledge in Kennedy's specific context, and

3. evaluating the impact of new practices.

For example, in the early stages of the program, Kennedy expressed interest in understanding how it could better inspire students to engage deeply in learning. The staff (including after school staff, and other school support staff) then participated in a day of learning with Stanford psychology professor Dr. Carol Dweck who presented her research on growth mindset (Dweck, 2007, 1986). After the presentation, participants considered what Dweck's framework would look like in practice. Participants first considered this question, "What would they see and hear that would be evidence of a growth mindset at Kennedy?" With concrete images in mind, they then considered, "How might we get from here to there? What steps could we take next week?" Participants then collectively designed an action plan of specific practices they could implement the following week. In the following monthly meetings of cross-role collaborative teams some time was set aside to reflect on the implementation and impact of these strategies. The combination of immediate and ongoing space to follow up allowed participants to integrate their own local knowledge with academic research knowledge in ways that informed and, in a few cases, changed practice to reflect a youth development approach.

\section{Work Area 4: Cultivate Habits of Shared Responsibility for a Youth Development Approach}

Throughout the implementation of YiM, the visioning team worked intentionally to grow the number of people in the school setting who understood, held, and moved intentionally toward a school-wide youth development approach. One core strategy that promoted shared responsibility was the development of an inquiry stance. For example, rather than mandate a school-wide effort to pursue a youth development approach, the leadership team framed their third year of YiM with the following question: "What practices (teaching strategies and school policies) can we use to create a more caring school community and motivate all students to learn?"Questions invite inquiry, curiosity, and engagement. Questions evoke a response. This question, in particular, reinforced the idea that "we," individuals across the setting, were invited and expected to respond.

At different points in the process to date, cross-role collaborative teams formed their own subquestions which led them to develop habits of inquiry, such as identifying priorities; forming 
authentic and researchable questions; reviewing relevant research and best practices; developing interventions; evaluating impact; and modifying practices in response to this cycle of inquiry.

For example, one team took the idea of creating a more caring school community and honed in on the setting's discourse - or the way people talk to and about others in the school setting.

Through this focus, school members have become more aware of how they speak about others and staff have a growing sense that they are responsible not only for their own discourse, but also for engaging their colleagues in ways that invite more positive discourse. Another team has looked at student interactions and developed practices that acknowledged and celebrated caring actions between students.

\section{Evidence of Positive Impact}

After year two of implementing YiM in concert with other efforts at Kennedy, there is preliminary evidence of progress in four areas:

1. A significant number of adults in the school setting have a working understanding of youth development.

One third of the staff reported an increased understanding of youth development and they can articulate a youth development approach and its connection to learning.

Our vision has been defined by looking at youth development...I have heard very positive feedback from the teachers like, 'Yes, we need this.' It's not 'we want it' it's 'we need it.'... We are all clear that even though it's the academics that are extremely important, our focus is on youth development and academics are part of youth development. (Administrator)

2. Adults are reframing students as youth in the middle of multiple interactive settings.

Adults in the school are aware that their students are young people first -that "student" is but one part of their identity and "school" is but one part of their landscape. Adults are consciously building stronger relationships with youth and other adults and view them as partners in supporting youth.

I have been trying to be very deliberate about making sure that I connect with the kids. I'm listening to them...to pick up on things that may be bothering them. (Teacher)

I used to think that schoolwork wasn't as important as after-school activities. Now I have a more collaborative relationship with teachers. (After-school Staff Member)

I have a greater understanding and appreciation for [after-school program] personnel. (Teacher)

We are building more relationships. The kids, instead of only having one favorite teacher in the team, I'm hearing three or four favorite teachers in the team. (Teacher) 
3. Adults are beginning to change practices to engage multiple domains of youth development in the service of intellectual development.

Teachers are experimenting with practices that acknowledge and engage the strengths of the young adolescent. For example, young adolescents often long to be of value and demonstrate mastery but they are worried about making mistakes and looking foolish in front of their peers. One teacher's effort to intentionally connect to this longing had a profound effect on one student:

At first I didn't know... how to write a sentence in parallel structure. I was worried... After you gave me that blue piece of paper that said, "If at first you don't succeed, try, try again." I was challenging myself to try, try again. I kept trying and finally, I understood. I felt proud. ( $8^{\text {th }}$ grade student)

\section{Overall school climate is more conducive to youth development.}

Adults in the school community report that the school climate and overall tone feel much improved and reflective of an environment that supports youth development.

I think that coming into this year...on day one, week one, there was just a complete change in the environment. I think just happier people from staff to students. (After-school Director, referring to the shift between year one and year two of YiM)

\section{Conclusion}

For over two decades, school reform literature has reminded us that we cannot mandate, force, or rush cultural or normative organizational changes (Fullan, 1993; Oakes 2005). With this in mind, YiM focused on intentionally pursuing a school culture reflective of a youth development approach through by focusing on four areas of work that would sustain and foster change over a long period of time. Evidence suggests that this program is fostering some changes to the school setting that will promote students' growth and development - inclusive of, but not limited to - the intellectual domain. We are extremely encouraged by Kennedy's courageous effort to situate its attention to academic achievement and other core goals within the context of youth development, and we are heartened by the evidence that this approach can result in positive changes.

The lessons shared in this article were learned through the hard work of incredible colleagues navigating a very difficult season in public education. This is but one snapshot of their longterm commitment to serving young people in their community. As we go to press, Kennedy's community is working tirelessly to sustain the good work that it has begun and to move through the next phase of the change process in ways that honor a youth development approach and effectively foster student learning and achievement.

For more information on YiM and to download tools and resources to support your efforts to implement a youth development approach in your setting, visit the John W. Gardner Center for Youth and Their Communities at http://jgc.stanford.edu. 


\section{References}

Center on Educational Policy. (2009). Compendium of major NCLB studies. Full text available at www.cep-dc.org.

Darling-Hammond, L. (2007). Testimony before the House Education and Labor Committee on the Re-Authorization of No Child Left Behind. Full text available at www.srnleads.org.

Dweck, C.S. (2007). The secret to raising smart kids. Scientific American Mind.

December/January, 36-43.

Dweck, C.S. (1986). Motivational processes affecting learning. American Psychologist, 41(10), 1040-1048.

Fullan, M. (1993). The new meaning of educational change. New York: Teachers College.

National Center for Educational Statistics. (2007). Changes in instructional hours in four subjects by public school teachers of grades one through four. (Issue brief). Full text available at www.nces.ed.gov.

Oakes, J. (2005). Keeping track: How schools structure inequality, Second edition. Yale: Yale University.

Teachers Network. (2007). Results of NCLB Survey. Full text available at www.teachersnetwork.org/tnli.

(C) Copyright of Journal of Youth Development Bridging Research and Practice. Content may not be copied or emailed to multiple sites or posted to a listserv without copyright holder's express written permission. However, users may print, download or email articles for individual use. 